Psychopharmacology 53, 321 (1977)

\title{
Erratum
}

\section{Open-field Behaviour in Sheep following Treatment with the Neuroleptics Azaperone and Acetylpromazine}

R. N. HUGHES, L. A. SYME, and G. J. SYME

Psychopharmacology 52, $107-109$ (1977)

On page 108, right column, line 14 should read:

$\ldots$ it was necessary to combine data from the drug conditions to produce a saline $(N=8)$ and one drug group $(N=16)$ for each compound separately. 